\title{
Hubungan Berat Badan Bayi Baru Lahir dengan Rupture Perineum Pada Persalinan Normal di Ruang Shafa RSI Siti Khadijah Palembang Tahun 2019
}

\section{Desi Hariani}

STIK Siti Khadijah Palembang

\section{Informasi Artikel :}

Diterima : 28 Maret 2020

Diperbaiki :07 April 2020

Disetujui : 20 April 2020

"Korespondensi Penulis : desinetra@yahoo.com

\begin{abstract}
A B S T R A K
Persalinan seringkali mengakibatkan perlukaan jalan lahir atau yang disebut dengan rupture perineum. Berat badan bayi baru lahir berpengaruh pada peregangan perineum, namun rupture perineum masih terjadi meskipun bayi yang lahir dilahirkan tidak terlalu besar. Tujuan penelitian ini untuk mengetahui hubungan berat badan bayi baru lahir dengan rupture perineum pada persalinan normal di Ruang shafa RSI Siti Khadijah Palembang Tahun 2020. Penelitian ini dilaksanakan pada tanggal 22 Januari -09 Maret Tahun 2020. Desain penelitian yang digunakan adalah metode Survey Analitik dengan pendekatan Cross Sectional dan menggunakan data analisis univariat dan bivariat, teknik pengambilan sampel dalam penelitian ini menggukan total sampling. Populasi dalam penelitian ini semua ibu bersalin yang melahirkan di Ruang shafa RSI Siti Khadijah Palembang pada Januari sampai dengan Maret 2020 sebanyak 40 responden. Analisis data dalam penelitian ini menggunakan uji Chi Square. Hasil penelitian ini menunjukkan bahwa dari 40 responden ibu yang mengalami rupture perineum sebanyak 30 responden $(75,0 \%)$ dan yang tidak mengalami rupture perineum sebanyak 10 responden $(25,0 \%)$. Terdapat hubungan yang signifikan antara berat badan bayi baru lahir dengan rupture perineum pada persalinan normal di Ruang shafa RSI Siti Khadijah Palembang dengan nilai $p$ value $0,031<\mathrm{a} 0,05$. Adapun saran yang diberikan untuk ibu agar meningkatkan deteksi dini dan pemantauan tumbuh kembang janin serta memberikan KIE kepada ibu hamil tentang berat badan bayi baru lahir dengan laserasi jalan lahir.
\end{abstract}

\section{Kata Kunci : Berat badan bayi baru lahir dan Rupture} perineum.

\section{ABSTRACT}

Delivery is often cause an injury to the birth canal or so-called rupture perineum. Newborn weight has an effect on perineal stretching, but rupture perineum still occurs even if the baby born is not too big. The aim of this research is to know the relationship of newborn weight and rupture perineum on normal delivery at Ruang shafa RSI Siti Khadijah Palembang in 2020. This research was conducted on January 22 to March 09, 2020. The research design used an Analytical Survey method with Cross Sectional approach and using univariate and bivariate analysis data, sampling technique in this research was total sampling. The population in this study was all maternity mothers who gave birth at Ruang shafa RSI Siti Khadijah Palembang from January to March 2020 as many as 40 respondents. Data analysis in this study using Chi Square test. The results of this study indicated that from 40 respondents of mothers who experienced rupture perineum as many as 30 respondents (75.0\%) and who did not experience rupture perineum as much as 10 respondents (25.0\%). There was a 
significant correlation between newborn weight with rupture perineum at normal delivery in Ruang shafa RSI Siti Khadijah Palembang with $p$ value 0,031 < a 0,05. Monitoring of fetal growth and giving KIE to pregnant women about the weight of newborn with laceration of birth canal.

Keywords : Newborn's weight and rupture perineum.

\section{PENDAHULUAN}

Persalinan dan kelahiran merupakan kejadian fisiologis yang setiap wanita hamil pasti akan mengalaminya. Persalinan adalah proses dimana bayi, plasenta, dan selaput ketuban yang telah cukup bulan atau dapat hidup di luar kandungan melalui jalan lahir dengan bantuan atau tanpa bantuan ${ }^{9}$

Fokus asuhan persalinan normal saat ini adalah persalinan bersih dan aman serta mencegah terjadinya komplikasi. Dengan paradigma pencegahan, episiotomi tidak lagi dilakukan secara rutin karena dengan parasat khusus, penolong persalinan akan mengatur ekspulsi kepala, bahu, dan seluruh tubuh bayi untuk mencegah laserasi atau hanya terjadi robekan minimal pada perineum ${ }^{26}$

Rupture perineum merupakan salah satu trauma yang paling sering diderita perempuan pada saat persalinan ${ }^{13}$ Rupture perineum adalah luka pada perineum yang diakibatkan oleh rusaknya jaringan secara alamiah karena proses desakan kepala janin atau bahu saat persalinan ${ }^{8}$

Hasil penelitian ini ada kesesuaian dengan teori $^{19}$, semakin besar berat bayi yang dilahirkan meningkatkan resiko terjadinya rupture perineum. Hal ini terjadi karena semakin besar berat badan bayi yang dilahirkan akan meningkatkan resiko terjadinya rupture perineum karena perineum tidak cukup kuat menahan regangan kepala bayi dengan berat badan bayi yang besar, sehingga pada proses bayi dengan berat badan bayi yang besar sering terjadi rupture perineum.

Menurut World Health Organization (WHO) dinegara berkembang, kematian maternal berkisar antara 750-1000 per 100.000 kelahiran hidup,dibandingkan dengan Negara maju, kematian maternal berkisar antara 5-10 perkelahiran hidup ${ }^{7}$. Kesehatan ibu dan anak perlu mendapat perhatian karena ibu hamil dan bersalin merupakan masalah besar Negara miskin dan berkembang seperti Indonesia. Komplikasi kehamilan, persalinan dan nifas merupakan penyebab terbesar kematian ibu di Indonesia ${ }^{17}$

Di Asia masalah rupture perineum cukup banyak dalam masyarakat, $50 \%$ dari kejadian rupture perineum di dunia terjadi di Asia.
Rupture perineum dialami oleh $85 \%$ wanita yang melahirkan pervaginam. pada golongan umur 2530 tahun yaitu $24 \%$ sedang pada ibu bersalin usia 32-39 tahun sebesar 62\%. Rupture perineum perlu mendapatkan perhatian karena dapat menyebabkan disfungsi organ reproduksi wanita, sebagai sumber perdarahan, dan sumber atau jalan keluar masuknya infeksi, yang kemudian dapat menyebabkan kematian karena perdarahan atau sepsis ${ }^{4}$

Berdasarkan Survey Demografi Kesehatan Indonesia (SDKI) tshun 2013 AKI Indonesia masih cukup tinggi yaitu sebesar 248 per 100.000 kelahiran hidup, angka tersebut masih tertinggi di Asia, sementara target Rencana Pembangunan Jangka Menengah Nasional (RPJMN) sebesar 226 per 100.000 kelahiran hidup. Penyebab terbesar kematian ibu yang terjadi pada masa nifas yaitu perdarahan $28 \%$, eklampsi $24 \%$, infeksi $11 \%$, rupture perineum $8 \%$.

Angka kematian ibu di Sumatra Selatan pada tahun 2012 akibat komplikasi kehamilan dan persalinan mencapai 133/100.000 kelahiran hidup, tahun 2013 angka kematian ibu di Sumatera Selatan 149/100.000 kelahiran hidup dan di tahun 2014 angka kematian ibu di Sumatera Selatan mencapai 146/100.000 kelahiran hidup dan beberapa faktor penyebab tinggi nya angka kematian ibu di Sumatra Selatan yaitu; Perdarahan (28\%), Eklamsia (24\%), Infeksi (11\%), Abortus (5\%), Partus Lama (5\%), Emboli (3\%), Komplikasi masa nifas (6\%), usia ibu > 35 tahun (14,9\%), anak > $3(10,3 \%)$, ibu hamil Kekurangan Energi Kronis (4,3\%), rupture perineum (5\%), ibu hamil dengan Anemia $(6,6 \%)$, usia ibu $>20$ tahun $(6,9 \%)$, jarak kehamilan $<2$ tahun $(2,5 \%)$ dan lain-lain $(11 \%)$ (Dinkes Sumsel, 2017).

Laporan Dinas Kesehatan Kota Palembang tahun 2012 angka kematian ibu akibat komplikasi kehamilan dan persalinan mencapai 11/30.305 kelahiran hidup, pada tahun 2013 angka kematian ibu sebanyak 13/32.841 kelahiran hidup, pada tahun 2014 ada 13/29.911 kelahiran hidup dan beberapa faktor penyebab tingginya angka kematian ibu di kota Palembang yaitu; Pre Eklamsi Berat (31\%), Hipertensi Dalam Kehamilan (23\%), Perdarahan (15\%), Persalinan lama (8\%), Syok Hivopolemik (8\%), ibu hamil 
dengan Hiperemesis Gravidarum (5,4\%), usia ibu $>35$ tahun (17,9\%), anak>3 (14,3\%), ibu hamil Kekurangan Energi Kronis(14,3\%), ibu hamil dengan Anemia $(10,6 \%)$, rupture perineum $(8,3 \%)$, usia ibu $>20$ tahun $(7,9 \%)$, Ketuban Pecah Dini $(7,3 \%)$, jarak kehamilan $<2$ tahun $(4,5 \%)$, Abortus $(4,4 \%)$, dan Perdarahan $(2,9 \%)^{6}$

Berdasarkan hasil studi pendahuluan yang dilakukan Ruang shafa RSI Siti Khadijah Palembang Tahun 2020 pada tiga tahun terakhir didapatkan data ibu yang bersalin pada tahun 2015 sebanyak 85 orang, dari 85 orang ibu yang melahirkan bayi dengan berat bayi lahir $<2500$ gram sebanyak 5 orang ibu mengalami rupture perineum, ibu yang melahirkan dengan berat bayi lahir 2500-4000 gram sebanyak 40 orang ibu yang mengalami rupture perineum dan ibu yang melahirkan $>4000$ gram sebanyak 15 orang ibu yang mengalami rupture perineum, serta sisanya 25 orang ibu yang tidak mengalami rupture perineum. Pada tahun 2018 sebanyak 80 orang, dari 80 orang ibu yang melahirkan bayi dengan berat bayi lahir <2500gram sebanyak 4 orang ibu yang mengalami rupture perineum, ibu yang melahirkan dengan berat bayi lahir 2500-4000 gram sebanyak 36 orang ibu yang mengalami rupture perineum dan ibu yang melahirkan berat bayi lahir $>4000$ gram sebanyak 20 orang ibu yang mengalami rupture perineum, dan sisanya 20 orang ibu yang tidak mengalami rupture perineum. Sedangkan bulan Januari-Maret 2020 yakni didapatkan data ibu yang bersalin sebanyak 40 orang, dari 40 orang ibu yang melahirkan bayi dengan berat bayi lahir <2500 gram sebanyak 2 orang ibu yang mengalami rupture perineum, ibu yang melahirkan dengan berat bayi lahir 25004000 gram sebanyak 26 orang ibu yang mengalami rupture perineum dan ibu yang melahirkan >4000 gram sebanyak 2 orang ibu yang mengalami rupture perineum. Serta sisanya 10 orang ibu yang tidak mengalami rupture perineum.

Dari uraian di atas maka penulis tertarik untuk melakukan penelitian dengan judul "Hubungan Berat Badan Bayi Baru Lahir dengan Rupture Perineum Pada Persalinan Normal di Ruang shafa RSI Siti Khadijah Palembang Tahun 2020

\section{METODE PENELITIAN}

Penelitian ini menggunakan desain penelitian survey analitik dengan pendekatan Cross Sectional dimana variabel independen dan variabel dependen di observasi hanya sekali pada saat yang sama. Kemudian melakukan analisis dinamika korelasi antara hubungan berat badan bayi baru lahir dengan rupture perineum pada persalinan normal di Ruang shafa RSI Siti Khadijah Palembang Tahun 2020. Populasi dalam penelitian ini adalah semua data ibu bersalin yang datang untuk melahirkan di Ruang shafa RSI Siti Khadijah Palembang pada bulan Januari sampai dengan Maret Tahun 2020 sebanyak 40 ibu bersalin. Sampel diambil dengan teknik total sampling.

\section{HASIL PENELITIAN}

\section{Analisa Univariat}

Analisa univariat dilakukan terhadap ditribusi frekuensi dan presentase dari masingmasing variabel independent (berat badan bayi baru lahir) dan variabel dependent (rupture perineum). Analisis disajikan dalam bentuk table distribusi dan teks.

\begin{tabular}{|c|c|c|}
\hline \multicolumn{3}{|c|}{$\begin{array}{l}\text { a. Berat Badan Bayi Baru Lahir } \\
\text { Tabel } 1 \text { Distribusi Frekuensi Berat Badan } \\
\text { Bayi Baru Lahir Pada Persalinan } \\
\text { Normal di Ruang shafa RSI Sit } \\
\text { Khadijah Palembang Tahun 2020 }\end{array}$} \\
\hline Berat Badan Lahir & Frekuensi & Persen \\
\hline$<2500$ gram & 6 & $15,0 \%$ \\
\hline $2500-4000$ gram & 31 & $77,5 \%$ \\
\hline$>4000 \mathrm{gr}^{\mathrm{c}}$ & 3 & $7,5 \%$ \\
\hline & 40 & \\
\hline
\end{tabular}

Berdasarkan tabel 1 di atas menunjukkan bahwa dari 40 responden yang melahirkan bayi dengan berat badan bayi baru lahir 2500-4000 gram sebanyak 31 responden $(77,5 \%)$ lebih tinggi dibandingkan dengan responden yang melahirkan bayi dengan berat badan bayi baru lahir <2500 gram sebanyak 6 responden $(15,0 \%)$ dan responden yang melahirkan dengan berat badan bayi baru lahir >4000 gram sebanyak 3 responden $(7,5 \%)$.

\section{b. Rupture Perineum.}

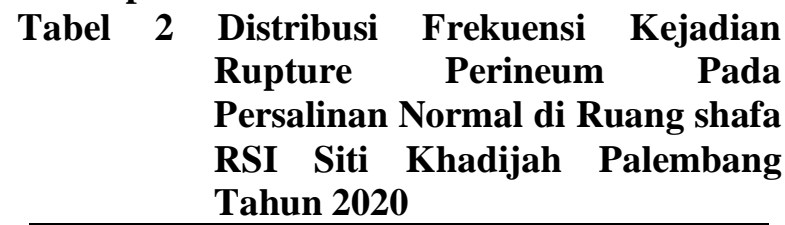

\begin{tabular}{ccc}
\hline Rupture perineum & Frekuensi & Persen \\
\hline Ya & 30 & $75,0 \%$ \\
\hline Tidak & 10 & $25,0 \%$ \\
\hline Total & $\mathbf{4 0}$ & $\mathbf{1 0 0 , 0}$ \\
\hline
\end{tabular}

Berdasarkan tabel 1.2 di atas menunjukkan bahwa dari 40 responden yang mengalami rupture perineum sebanyak 30 responden $(75,0 \%)$ lebih tinggi dibandingkan yang tidak mengalami 
rupture perineum sebanyak 10 responden $(25,0 \%)$.

\section{Analisa Bivariat}

a. Berat Badan Bayi Baru Lahir

Tabel 3 Distribusi Frekuensi Berat Badan Bayi Baru Lahir Pada Persalinan Normal di Ruang shafa RSI Siti Khadijah Palembang Tahun 2020

\begin{tabular}{ccc}
\hline Berat Badan Lahir & Frekuensi & Persen \\
\hline$<2500$ gram & 6 & $15,0 \%$ \\
\hline $2500-4000$ gram & 31 & $77,5 \%$ \\
\hline$>4000$ gram & 3 & $7,5 \%$ \\
\hline Total & $\mathbf{4 0}$ & $\mathbf{1 0 0 , 0}$ \\
\hline
\end{tabular}

Berdasarkan tabel 3 di atas menunjukkan bahwa dari 40 responden yang melahirkan bayi dengan berat badan bayi baru lahir 2500-4000 gram sebanyak 31 responden $(77,5 \%)$ lebih tinggi dibandingkan dengan responden yang melahirkan bayi dengan berat badan bayi baru lahir <2500 gram sebanyak 6 responden $(15,0 \%)$ dan responden yang melahirkan dengan berat badan bayi baru lahir >4000 gram sebanyak 3 responden $(7,5 \%)$.

\section{b. Rupture Perineum.}

Tabel 4Distribusi Frekuensi Kejadian Rupture Perineum Pada Persalinan Normal di Ruang shafa RSI Siti Khadijah Palembang Tahun 2020

\begin{tabular}{ccc}
\hline Rupture perineum & Frekuensi & Persen \\
\hline Ya & 30 & $75,0 \%$ \\
\hline Tidak & 10 & $25,0 \%$ \\
\hline Total & $\mathbf{4 0}$ & $\mathbf{1 0 0 , 0}$ \\
\hline
\end{tabular}

Berdasarkan tabel 4 di atas menunjukkan bahwa dari 40 responden yang mengalami rupture perineum sebanyak 30 responden $(75,0 \%)$ lebih tinggi dibandingkan yang tidak mengalami rupture perineum sebanyak 10 responden $(25,0 \%)$.

\section{Analisa Bivariat}

Analisa bivariat yang digunakan adalah tabulasi silang antara dua variabel yaitu variabel independent dan dependent. Analisa bivariat yang digunakan untuk mengetahui hubungan terhadap objek penelitian adalah menggunakan Check List.

Analisa ini dilakukan antara variabel independent (berat badan bayi baru lahir), variabel dependent (rupture perineum) menggunakan uji statistik. Uji statistic yang digunakan adalah Chi-Square dengan menggunakan komputerisasi dimana batas kemaknaan $p$ value $\alpha=0,05$ dengan keputusan, yaitu :

a. Jika $\mathrm{p}$ value $\leq \alpha$ yang berarti ada hubungan antara variabel independent dan variabel dependent.

b. Jika $\mathrm{p}$ value $>\alpha$ berarti tidak ada hubungan antara variabel independent dan variabel dependent.

\section{Hubungan Berat Badan Bayi Baru Lahir dengan Rupture}

Tabel 5 Tabulasi Silang anatar Berat Badan Bayi Baru Lahir dengan Rupture Perineum Pada Persalinan Normal di Ruang shafa RSI Siti Khadijah Palembang Tahun 2020

\begin{tabular}{ccccc}
\hline $\begin{array}{c}\text { Berat bayi } \\
\text { lahir }\end{array}$ & \multicolumn{2}{c}{ Rupture perineum } & Total & $\begin{array}{c}\mathbf{p} \\
\text { value }\end{array}$ \\
\cline { 2 - 3 } & ya & Tidak & & 0,031 \\
& 2 & 4 & 6 & $0,030)$ \\
\hline 2500 gram & $(33,3 \%)$ & $(66,7 \%)$ & $(15,0 \%)$ & \\
\hline $\begin{array}{c}2500-4000 \\
\text { gram }\end{array}$ & 26 & 5 & 31 & \\
\hline$>400$ gram & 2 & 1 & 3 & \\
& $(66,9 \%)$ & $(16,1 \%)$ & $(77,5 \%)$ & \\
\hline Total & 30 & 10 & 40 & \\
\hline
\end{tabular}

Berdasarkan tabel 5 terdapat sebanyak 31 responden, dari 31 responden yang melahirkan bayi dengan berat badan bayi lahir antara 25004000 gram yang mengalami rupture perineum sebanyak 26 responden $(15,0 \%)$ lebih tinggi dibandingkan dari 6 responden yang melahirkan bayi dengan berat badan bayi lahir <2500 gram yang mengalami rupture perineum sebanyak 2 responden $(33,3 \%)$ dan 3 responden yang melahirkan bayi dengan berat badan bayi lahir $>4000$ gram yang mengalami rupture perineum sebanyak 2 responden $(66,7 \%)$.

Sesuai hasil uji statistik chi square diperoleh nilai $p$ value 0,031 yang dimana $p<a=$ 0,05 sehingga dapat disimpulkan bahwa terdapat hubungan yang signifikan antara berat badan bayi baru lahir dengan rupture perineum. Jadi hipotesis yang menyatakan bahwa "Ada hubungan Berat Badan Bayi Baru Lahir dengan Rupture Peineum Pada Persalinan Normal" terbukti kebenarannya.

\section{PEMBAHASAN}

\section{Analisa Univariat}

\section{a. Berat badan bayi baru lahir}

Dari hasil penelitian diketahui bahwa dari 40 responden yang melahirkan bayi dengan berat badan bayi baru lahir antara 2500-4000 gram sebanyak 31 responden $(77,5 \%)$ lebih tinggi 
dibandingkan dengan responden yang melahirkan bayi dengan berat badan bayi baru lahir $<2500$ gram sebanyak 6 responden $(15,0 \%)$ dan responden yang melahirkan bayi dengan berat badan bayi baru lahir >4000 gram sebanyak 3 responden $(7,5 \%)$.

Menurut Yanti, 2009 bahwa bayi sedang sampai besar memiliki resiko yang dapat terjadi pada ibu bila kondisi panggul patologik yaitu terjadinya kesulitan dalam melahirkan, perdarahan pasca bersalin, dan robekan jalan lahir. Sedangkan masalah pada janin diantaranya dapat terjadi asfiksia, bahu dapat tersangkut, bayi akan lahir dengan gangguan nafas, trauma leher dan gawat janin ${ }^{18}$

Berat badan bayi yang normal dilahirkan oleh seorang ibu adalah antara 2500-4000 gram, karena pada berat tersebut menunjukkan bahwa selama didalam kandungan nutrisi bayi terpenuhi dan biasanya pada berat 2500-4000 gram bayi sudah mampu beradaptasi di luar kandungan untuk menyesuaikan diri dengan lingkungan baru $^{25}$

Penting bagi seorang ibu hamil untuk melakukan pemeriksaan ultrasonografi (USG) dan pemeriksaan kadar gula dalam darah selama kehamilan. Pemeriksaan besar bayi dengan menggunakan USG memberikan ketepatan sampai $90 \%$ sedangkan mengukur tinggi fundus uteri hanya memberikan ketepatan sampai 50\%. Pada pemeriksaan kadar gula dalam darah sangat diperlukan untuk mencegah terjadinya komplikasi kematian janin dalam kandungan karena ibu dengan riwayat sakit gula mengakibatkan ibu melahirkan bayi besar. Bila kadar gula dalam darah tidak normal, dapat dinomalkan dengan menggunakan suntikan hormon insulin. Sehingga jangan malu untuk menceritakan riwayat kehamilan yang buruk jika sedang berkonsultasi dengan dokter ${ }^{18}$ Penellitian ini sejalan dengan penelitian yang dilakukan oleh Enggar tahun 2012 dengan judul hubungan berat badan bayi baru lahir dengan kejadian rupture perineum di BPM Rosida Himawati Kabupaten Purworejo mendapatkan hasil berat badan bayi baru lahir $<2500-3000$ gram sebanyak 80 bayi $(48,, 5 \%)$, berat badan bayi baru lahir >3000-3500 gram sebanyak 61 bayi (37\%) dan berat bayi lahir>3500-4000 gram sebanyak 24 (14,5\%) bayi dari 165 kelahiran.

Penelitian ini sejalan dengan Puspita tahun 2013 yang berjudul hubungan berat badan bayi dengan robekan perineum pada persalinan fisiologis di RB Lilik Sidoarjo mendapatkan hasil berat badan bayi baru lahir <2500 gram sebanyak
7(28\%), berat badan bayi baru lahir 2500-4000 gram sebanyak $18(72 \%)$ dan berat badan bayi baru lahir >4000 gram sebanyak $0(0 \%)$.

Berdasrkan penelitian yang telah dilakukan peneliti berpendapat bahwa di Ruang shafa RSI Siti Khadijah Palembang Tahun 2020

Responden yang melahirkan berat badan bayi baru lahir rata-rata memiliki berat badan bayi lahir normal antara 2500-4000 gram. Berat badan bayi baru lahir sebaiknya jangan terlalu besar atau kecil. Jika ibu melahirkan berat badan bayi besar ditakutkan mengakibatkan resiko yang tidak inginkan pada ibu dan bayi.

\section{b. Kejadian Rupture Perineum}

Dari hasil penelitian diketahui bahwa dari 40 responden yang mengalami rupture perineum sebanyak 30 responden $(75,0 \%)$ lebih tinggi dibandingkan yang tidak mengalami rupture perineum sebanyak 10 responden $(25,0 \%)$.

Rupture perineum terjadi hampir semua persalinan pertama dan tidak jarang juga pada persalinan berikutnya. Rupture ini dapat dihindarkan atau dikurangi dengan menjaga jangan sampai dasar panggul dilalui oleh kepala janin dengan cepat. Sebaliknya janin yang akan lahir jangan di tahan terlampau kuat dan lama, karena akan menyebabkan asfiksia dan perdarahan dalam tengkorak janin dan melemahkan otot-otot dan fasia pada dasar panggul karena direnggangkan terlalu lama. ${ }^{21}$

Berdasarkan teori yang ada, rupture perineum terjadi pada kelahiran dengan berat badan bayi yang besar. Hal ini terjadi karena semakin besar berat badan bayi yang dilahirkan akan meningkatkan resiko terjadinya rupture perineum karena perineum tidak cukup kuat menahan regangan kepala bayi dengan berat badan bayi lahir yang besar sering terjadi rupture perineum $^{25}$.

Hal ini dapat juga dihindari dengan cara mencegah dan menangani agar tidak terjadi rupture perineum yaitu pemijatan perineum yang dilakukan beberapa minggu sebelum bersalin untuk melumaskan otot-otot disekitar perineum menjadi lentur dan lebih meregang pada saat melahirkan, lakukan senam kegel untuk mencegah lemahnya sfingter uretra atau otot yang digunakan untuk berkemih dan nutrisi bagi ibu juga sangat diperlukan untuk membantu mengelastiskan kulit agar perineum dapat meregang selama melahirkan ${ }^{31}$.

Penelitian ini sejalan dengan Yuniarti tahun 2012 yang berjudul hubungan berat bayi lahir dengan kejadian rupture perineum pada persalinan normal di BPM Desy Andri Anita 
Surabaya Tahun 2012. Didapatkan hasil 64 responden, dari 64 responden $39(60,09 \%)$ responden yang mengalami rupture perineum dan $25(39,1 \%)$ responden yang tidak mengalami rupture perineum.

Penelitian ini sejalan dengan Sulistiyani tahun 2015 yang berjudul hubungan antara berat badan bayi baru lahir dengan kejadian rupture perineum pada ibu bersalin spontan di BPM Endang Minaharsi Am.Keb Kabupaten Ngemplak Simongan Semarang Barat Tahun 2015. Didapatkan hasil 100 responden, dari 100 responden $71(71,0 \%)$ yang mengalami rupture perineum dan $29(29,0 \%)$ yang tidak mengalami rupture perineum.

Berdasarkan hasil penelitian, teori dan penelitian terkait maka peneliti berasumsi bahwa berat badan bayi baru lahir bisa mempengaruhi rupture perineum. Didapatkan bahwa responden yang mengalami rupture perineum lebih banyak dibandingkan yang tidak mengalami rupture perineum.

\section{Analisa Bivariat}

\section{a. Hubungan Berat Badan Bayi Lahir dengan Rupture Perineum}

Dari hasil penelitian diketahui bahwa dari

31 responden yang melahirkan bayi dengan berat badan bayi baru lahir antara 2500-4000 gram yang mengalami rupture perineum sebanyak 26 responden $(83,9 \%)$ lebih tinggi dibandingkan dari 6 responden yang melahirkan bayi dengan berat badan bayi baru lahir <2500 gram yang mengalami rupture perineum sebanyak 2 responden $(33,3 \%)$ dan dari 3 responden yang melahirkan bayi dengan berat badan bayi baru lahir >4000 gram yang mengalami rupture perineum sebanyak 2 responden $(66,7 \%)$.

Bila dilihat pada nilai $\mathrm{p}$ value yaitu 0,031 yang berarti $\mathrm{p}<0,05$ dengan demikian maka Ho ditolak Ha diterima sehingga dapat disimpulkan "Ada Hubungan Berat Badan Bayi Baru Lahir dengan Rupture Perineum Pada Persalinan Normal di Ruang shafa RSI Siti Khadijah Palembang Tahun 2020".

Hasil kesimpulan diatas sesuai dengan yang diungkapkan Saifuddin (2006) yang menyatakan bahwa semakin besar bayi yang lahir melalui jalan lahir ibu maka dimungkinkan semakin besar pula robekan jalan lahir. Pada saat persalinan berat badan bayi lahir berpengaruh pada peregangan perineum sehingga pada perineum yang kaku mudah terjadi rupture. Pada saat persalinan, laserasi spontan pada perineum dapat terjadi pada saat kepala dan bahu dilahirkan. Ketika bayi melewati jalan lahir, berat badan bayi berpengaruh terhadap besarnya penekanan terhadap otot-otot perineum ini sering menyebabkan rupture perineum.

Penanganan yang dilakukan bila diketahui terdapat rupture perineum yaitu dilakukan penjahitan luka dengan baik lapis demi lapis dengan memperhatikan jangan ada robekan yang terbuka ke arah vagina yang biasanya dapat dimasuki oleh bekuan darah yang akan menyebabkan luka lama sembuh. Dan memberikan ibu antibiotik yang cukup agar tidak terjadi infeksi ${ }^{10}$

Perawatan rupture perineum dapat dilakukan setiap waktu yaitu pada saat mandi, setelah buang air kecil dan setelah buang air besar. Pada saat mandi ibu postpartum harus mengganti pembalut yang digunakan karena kemungkinan terjadi kontaminasi bakteri pada cairan yang tertampung dipembalut, serta diperlukan pula pembersihan pada perineum. Perawatan luka rupture perineum dilakukan juga pada saat setelah buang air kecil dan besar. Pada saat buang air kecil kemungkinan air seni pada rectum yang akan memicu pertumbuhan bakteri pada perineum sehingga diperlukan pembersihan. Sedangkan setelah buang air besar diperlukan pembersihan sisa-sisa kotoran yang berada disekitar anus untuk mencegah terjadinya kontaminasi bakteri dari anus ke perineum.

Hasil penelitian ini sejalan dengan hasil penelitian yang dilakukan oleh Widiyani dengan judul hubungan berat badan bayi baru lahir dengan kejadian rupture perineum pada persalinan spontan di BPM Rosmala Bukitinggi Tahun 2015 dari uji statistik mendapatkan nilai $\mathrm{p}$ value $0,03<$ a 0,05 yang artinya Ha diterima sehingga ada hubungan yang signifikan antara berat badan bayi baru lahir dengan kejadian rupture perineum terbukti.

Berdasakan hasil penelitiaan, teori dan penelitian terkait maka peneliti berasumsi bahwa salah satu penyebab rupture perineum adalah berat badan lahir, karena ibu yang melahirkan bayi dengan berat badan antara 2500-4000 gram dan >4000 gram perineum nya mengalami peregangan yang sangat kuat, sehingga resiko terjadinya rupture lebih besar, namun semua itu juga bisa saja dihalangi oleh keelastisitasan otot perineum, bisa ibu yang melahirkan berat badan bayi baru lahir antara 2500-4000 gram dan $>4000$ gram ridak terjadi rupture karena otot perineum yang elastis. Bahkan ibu yang melahirkan berat badan bayi baru lahir <2500 gram bisa mengalami rupture perineum bisa disebabkan oleh mengedan yang salah. 


\section{KESIMPULAN}

Dari 40 responden diperoleh responden yang melahirkan bayi dengan berat badan bayi baru lahir $<2500$ sebanyak 6 responden $(15,0 \%)$, responden yang melahirkan bayi dengan berat badan bayi baru lahir 2500-4000 gram sebanyak 31 responden $(77,5 \%)$ dan responden yang melahirkan bayi dengan berat badan bayi baru lahir $>4000$ gram sebanyak 3 responden $(7,5 \%)$. Dari 40 responden, 30 responden $(75,0 \%)$ yang mengalami rupture perineum dan sisanya 10 responden $(25,0 \%)$ yang tidak mengalami rupture perineum. Terdapat hubungan yang signifikan antara berat badan bayi baru lahir dengan rupture perineum pada persalinan normal di Ruang shafa RSI Siti Khadijah Palembang Tahun 2020 dengan nilai $p$ value $0,031<a 0,05$.

\section{SARAN}

\section{Bagi RSI Siti Khadijah Palembang}

Diharapkan dapat lebih meningkatkan kewaspadaan dalam melakukan pertolongan persalinan sehingga tidak terjadi rupture perineum dan diharapkan meningkatkan deteksi dini dan pemantauan tumbuh kembang janin serta memberikan KIE kepada ibu hamil tentang berat badan bayi baru lahir dengan laserasi jalan lahir.

\section{Bagi Peneliti Selanjutnya}

Diharapkan kepada peneliti selanjutnya diharapkan peneliti mengobservasi langsung ibu yang bersalin untuk mengetahui penyebab rupture perineum selain berat badan bayi baru lahir.

\section{DAFTAR PUSTAKA}

1. Arikunto, S. 2006. Prosedur Penelitian Suatu Pendekatan Praktik. Jakarta : Rineka Cipta.

2. Budiman, 2011. Penelitian Kesehatan. Yogyakarta : Refika Aditama.

3. Carey, J. 2005. Ilmu Kesehatan Obstetri Patologi Reproduksi Edisi 2. Jakarta : EGC.

4. Chapman, V. 2006. Asuhan Kebidanan Persalinan dan Kelahiran (The Midwife's Labour and Birth Handbook. Jakarta : EGC.

5. Cunningham, F.G. 2006. Obstetri Williams 1. Jakarta : EGC.

6. Dinkes Sumatera Selatan. 2014. Profil Kesehatan Provinsi Sumatera Selatan. Dikutip dari : www.dinkespalembang.go.id. Diakses tanggal 5 Juni 2017.

7. Enggar $\mathrm{P}, \mathrm{Y}$. Hubungan berat badan lahir dengan kejadian rupture perineum pada persalinan normal di RB Harapan Bunda di Surakarta Tahun 2012. Dikutip dari: $w w w$. Jurnalkesehatan.com. Diakses tanggal 10 Juli 2017.

8. JNPK-KR. 2007. Pelatihan Klinik Asuhan Persalinan Normal. Jakarta : Departemen Kesehatan Republik Indonesia.

9. Mayang Puspasari, Dwi. 2010. Faktor-faktor yang berhubungan dengan Rupture Perineum di BPS Cristin Sulastri Lamper KrajanSemarang.pdf. Dikutip dari : www.Jurnalkesehatan.com.Diakses tanggal 10 Juli 2017

10.Mochtar, R. 2007. Sinopsis Obstetri. Jakarta : EGC.

11.Notoatmodjo, S. 2016. Metodologi Penelitian Kesehatan. Jakarta : PT Rineka Cipta.

12.Nanny Lia Dewi, Vivian. 2010. Asuhan Kebidanan Pada Persalinan. Yogyakarta: Pustaka Pelajar.

13.Oxorn dan William. 2010. Ilmu Kebidanan Patologi Dan Fisiologi Persalinan. Yogyakarta : YEM.

14.Prawirohardjo, Sarwono. 2011. Ilmu Kebidanan. Jakarta : PT Buku Pustaka.

15.Pravitasari. 2009. Hubungan Berat Badan Lahir Dengan Rupture Perineum di BPS Alimah Bukit tinggi. Dikutip dari: http://www.Mediaindonesia.co.id. Diakses tanggal 10 Juni 2017.

16.Puspita. 2013. hubungan berat badan bayi dengan robekan perineum pada persalinan fisiologis di RB Lilik Sidoarjo. Dikutip dari: http://repositori.usu.ac.id. Diakses tanggal 15 Juli 2017.

17.Rofiasari. 2009. Hubungan Berat Badan Bayi Baru Lahir dengan kejadian Rupture Perineum pada persalinan spontan di RSUD Kota Surakarta. Dikutp dari: http://repositori.umy.ac.id. Diakses tanggal 10 Juni 2017 
18.Rukiyah dan Lia. 2010. Asuhan Kebidanan Patologi IV (Patologi Kebidanan). Jakarta : TIM.

19.Saiffudin A.B. 2008. Buku Panduan Praktis Pelayanan Maternal dan Neonatal. Jakarta : Yayasan Bina Pustaka Sarwono Prawirohardjo.

20.Siswosudarmo, Risanto \& Emilia. 2008. Obstetri Fisiologi. Yogyakarta : Pustaka Cendikia Press.

21.Suciana, Retno. 2006. "Hubungan Berat Badan Bayi Baru Lahir dengan Rupture Perineum." http://repository.unimus.ac.id. Diunduh tanggal 5 Juni 2017.

22.Saifudin A.B, 2008. Buku Acuan Nasional Pelayanan Kesehatan Maternal dan Neonatal. Jakarta : Yayasan Bina Pustaka Sarwono Prawirohardjo.

23.Sugiyono. 2007. Statistika untuk Penelitian. Bandung : Alfabeta.

24.Sulistiyani. 2015. hubungan antara berat badan bayi baru lahir dengan kejadian rupture perineum pada ibu bersalin spontan. Dikutip dari : http://repositori.unbraw.ac.id. Diakses tanggal 16 Juli 2017.

25.Varney, H. 2008. Buku Ajar Asuhan Kebidanan Volume 2. Jakarta : ECG.

26.Wiknjosastro, Hanifa. 2007. Ilmu Kebidanan Jakarta : Yayasan Biru Pustaka Sarwono Prawirohardjo.

27.Wahyuni, Sari. 2008. Asuhan Neonatus, Bayi, dan Balita. Jakarta : EGC.

28.Waspodo A. R, Danuatmaja, B. 2001. Asuhan Persalinan Normal. Jakarta : EGC.

29.Wahyuni, U. 2001. Rupture Perineum."http://www.midwiferyeducator.com .”. Diakses tanggal 5 Juni 2017.

30.Widiyani. 2015. hubungan berat badan bayi baru lahir dengan kejadian rupture perineum pada persalinan spontan di BPM Rosmala Bukittinggi Dikutip dari : medicalcenter.com. Diakses tanggal 16 Juli 2017.
31.Yanti. 2009. Buku Ajar Kebidanan Persalinan. Yogyakarta : Pustaka Rihana.

32. Yuniarti. 2012. hubungan berat bayi lahir dengan kejadian rupture perineum pada persalinan normal di BPM Desy Andri Anita Surabaya. Dikutip dari : http://naskahpublikasi.com. Diakses tanggal 15 Juli 2017 